\title{
Molecular characterization of eight horse breeds in Algeria using microsatellite markers
}

\author{
MOHAMMED EL AMINE BENAHAMADI ${ }^{1, \bullet}$, NAIMA BERBER ${ }^{2}$, MOHAMMED BENYAROU ${ }^{1}$, \\ ABDELKADER AMEUR AMEUR ${ }^{1}$, HADI YOUSSOUF HADDAM ${ }^{1}$, MOHAMMED PIRO $^{3}$, \\ SEMIR BECHIR SUHEIL GAOUAR ${ }^{1, \vee \vee}$ \\ ${ }^{1}$ Laboratory Physiopathology and Biochemistry of Nutrition (PpBioNut), Department of Biology, SNV-STU Faculty, University of Tlemcen, Algeria. \\ Tel.: +21-355-5681312, `email: moha-sywat@hotmail.fr \\ ${ }^{2}$ Laboratory of Biotoxicology, Pharmacognosy, and Biological Valorisation of Plant, University of Saida Algeria. ^vemail: naima.berber@univ-saida.dg \\ ${ }^{3}$ Veterinary Genomics Laboratory, Hassan II Agronomic and Veterinary Medicine Institute, Rabat, Morocco
}

Manuscript received: 21 May 2020. Revision accepted: 13 August 2020.

\begin{abstract}
Benahamadi MEA, Berber N, Benyarou M, Ameur Ameur A, Haddam HY, Piro M, Gaouar SBS. 2020. Molecular characterization of eight horse breeds in Algeria using microsatellite markers. Biodiversitas 21: 4107-4115. The Algerian horse population Barb, Origin Barb unknown, Arabian-Barb, Arabian, Thoroughbred (Pur sang); French Trotter, Algerian saddle, and Saddle are under a significant loss of genetic variability. This should be evaluated before any breed conservation and management program. For this purpose, genetic analyzes of diversity and differentiation were carried out on eight breeds horses reared in Algeria with 17 microsatellites. All microsatellite markers were highly polymorphic in all Breeds. A total of 170 alleles from 17 microsatellite loci were detected in 279 horses. The average number of alleles per locus was highest in Arabian-Barb horses (7.88) and lowest in Saddle breed (4.94). The observed heterozygosity interbreeds ranged from 0.685 to 0.625 for Barb and Saddle, while the expected heterozygosity was ranged from 0.746 to 0.678 for Arabian-Barb and Algerian Saddle respectively, the Ho value is lower than that of He value. Genetic diversity between breeds was significant, based on Fst. Three different approaches to assess genetic relationships have been applied; namely, genetic distances, factorial correspondence analysis, and admixture analysis have shown that a significant amount of genetic variation is maintained in populations of native horses and other breeds: the Barb, Arabian-Barb, Barb (Oi). Algerian Saddle and Saddle breeds appear to be the most genetically related and support that there are crosses between these two breeds.
\end{abstract}

Keywords: Algeria, genetic diversity, native horse breeds, microsatellites, population genetic structure

\section{INTRODUCTION}

In Algeria, animal genetic resources offer a great diversity of breeds in terms of their adaptation and production capacity in their natural environment. Equines are no exception to this observation. As such, they constitute a varied wealth, with high economic and socio-cultural importance.

The horse industry occupies a special place in the history and economy of North Africa (Benhamadi et al. 2016; 2017 and 2019) for a long time, the horse is a real player in sustainable development in Algeria, particularly in the environmental field. It plays an important role in the management of spaces and landscapes beneficial to the maintenance and development of biodiversity, but also its relationship with human, by contributing to sports, social and cultural activities. In this context, the development of equine breeding requires its rationalization and, therefore, the use of modern techniques for the management of equine genetic resources (Berber et al. 2016, Benhamadi et al. 2016, 2017, 2019).

The Algerian equine population has been estimated at approximately 250,000 horses, composed of $90 \%$ of Barb and Arabian-Barb and Algerian Saddle horses (Berber et al. 2016). The remaining $10 \%$ is divided between Arabian horses, Thoroughbreds, and French Trotters (Berber et al. 2016).
The DAD-IS database lists in 2018 two breeds of horses bred in Algeria: the Arabian-Barb and the Barb (DAD-IS consulted in October 2018). However, the Arabian (Élise Rousseau 2014), the Thoroughbred, and the French Trotter are also the subject of more or less important breeding (Berber et al. 2016). The cradle of the Barb and Arabianbarb horse in North Africa. They are generally used in fantasia (traditional horse-riding exhibition in the Maghreb at cultural festivals), as well as in the equestrian sports. Approximately 10,000 heads are belonging to the Barb breed and 80,000 to the Arabian-Barb heads (Berber et al. 2016, Benhamadi et al. 2016; 2017, 2019).

In 1886, the first Algerian studbook of the Barb horse was established. Tunisians and Moroccans followed in 1896 and 1914, respectively (Piro et al. 2019; Berber et al. 2016). The Arabian-Barb is the predominant Breed in Algeria as a creation of the broodmares of Tiaret in 1877, crossing between Barb and Arabian horses breeds (Berber et al. 2016). It combines the robustness and the endurance of the Barb horse, the elegance, and the speed of the Arabian horse. In addition, another Breed named Algerian Saddle breed was developed. It is the product of a cross between the Algerian Barb breed and the heavily French horses (Rayan 2015). The Arabian Breed, the Thoroughbred and the French Trotter, mainly used in equestrian sports, dressage, and show jumping events are 
mostly imported and distributed unevenly over Algerian territory and are well adapted to mountainous regions and arid lands of North Africa (Berber et al. 2016). Unfortunately, in recent years, breeders have started to make uncontrolled crosses between several breeds, which has mostly contributed to genetic pollution leading to serious identification ambiguity. The objective of this study is to carry out the genetic characterization of the eight breeds using 17 microsatellites, and to genetically identify the horse Barb as well as the Algerian Saddle The genetic characterization of the Barb horse (registered and of unknown origin), as well as the Algerian saddle, also aims to build a specific database for these breeds. This step is crucial for the improvement and preservation of our equine genetic heritage, which is undergoing the harmful hazards of inbreeding. Indeed, registering horses on a fundamental basis at the level of the existing stood-book has the immediate effect of restoring genetic variability and therefore restoring performance.

\section{MATERIALS AND METHODS}

\section{Animal samples}

The samples studied consisted of a total of 296 animals (201 of these were taken from a DNA bank of Berber et al. 2014) belonging to 8 equine breeds reared in different Algeria regions (Figure 1). About 219 animals (57\% of total samples) in this study are registered at the stud-book level, while the other 77 animals (26\% of total samples) were identified as belonging to a given breed with the help of ONEDEC (National Office for the Development of Equine and Camelin Livestock) expert and the OMCB (the World Barb Horse Organization). Our samples are spread over different Algerian regions known for horse breeding. The prospecting area represents $360,000 \mathrm{~km} 2$, which represents the surface of European payee like Germany. The origin and sample sizes of these eight breeds are presented in Table 1. The blood samples were taken in EDTA tubes $(5 \mathrm{~mL})$ from the jugular vein and were stored at $-20{ }^{\circ} \mathrm{C}$ until DNA extraction.

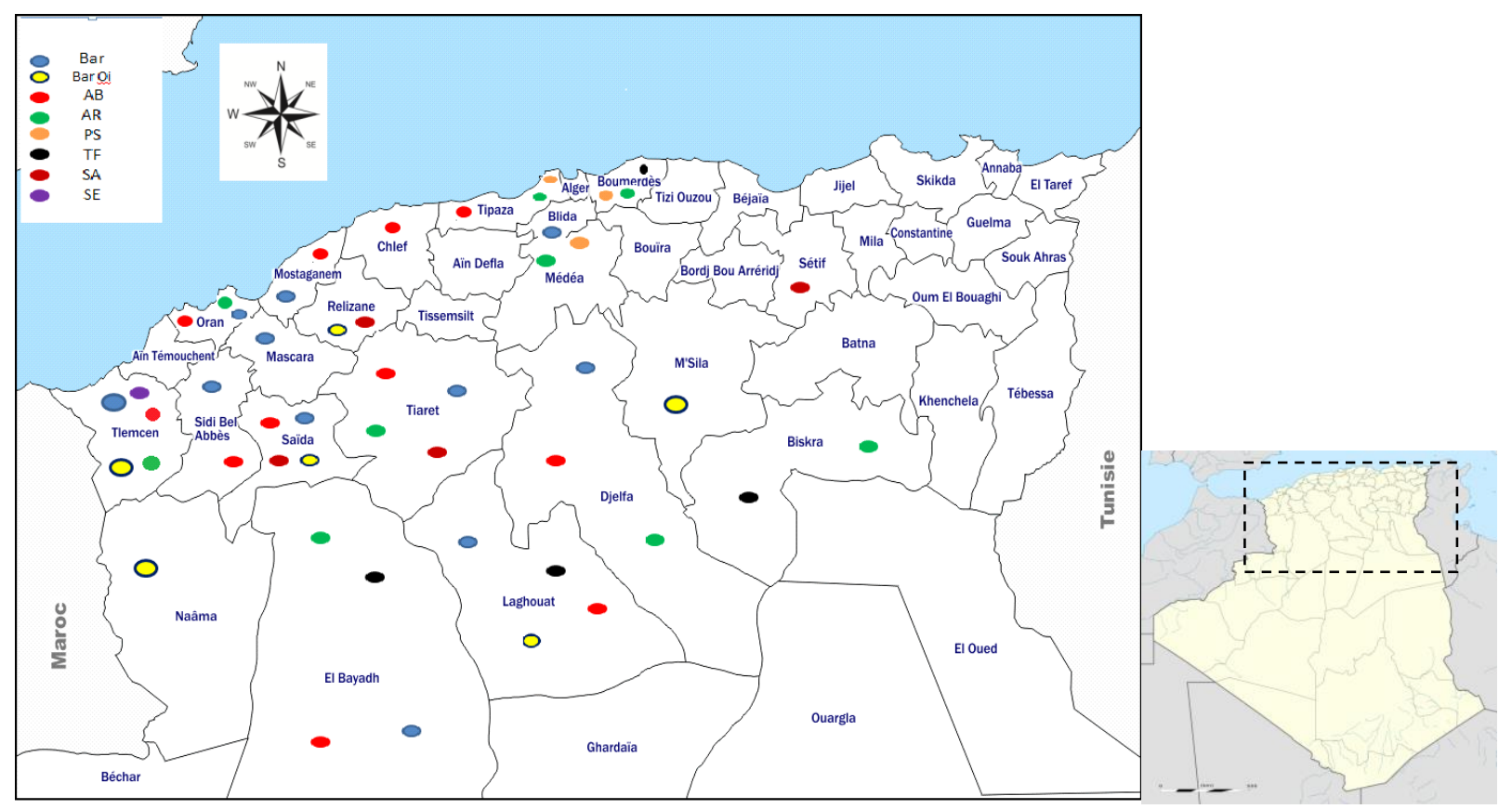

Figure 1. Map of sampling sites in Algeria for the eight equine breeds studied. Bar: Barb, Bar Oi: Origin Barb unknown, AB: ArabianBarb, AR: Arabian; PS: Thoroughbred (Pur sang); TF: French Trotter, SA: Algerian saddle, SE: Saddle

Table 1. Origin and size of the samples of the breeds studied

\begin{tabular}{llc}
\hline \multicolumn{1}{c}{ Breed } & \multicolumn{1}{c}{ Origin of samples } & $\begin{array}{c}\text { Number of } \\
\text { samples }\end{array}$ \\
\hline Barb & Tlemcen, Sidi Bel Abbes, El Bayedh, Saida, Oran, Mascara, Mostaganem, Tiaret, Laghouat, & 57 \\
Origin Barb unknown & Djelfa, Blida & Tlemcen, Naama, Saida, Laghouat, Relizaine, Msila \\
Arabian-Barb & Tlemcen, Sidi Bel Abbes, Oran, Saida, Mostaganem, Chlef, Tiaret, El Bayedh, Laghouat, Tipaza & 56 \\
Arabian & Tlemcen, El Bayedh, Oran, Tiaret, Médéa, Alger, Boumerdes, Djelfa, Biskra & 59 \\
French Trotter & El Bayedh, Laghouat, Biskra, Boumerdes & 26 \\
Thoroughbred & Alger, Médéa, Boumerdes & 21 \\
Algerian saddle & Tiaret, Saida, Relizaine, Sétif & 18 \\
Saddle & Tlemcen & 10 \\
Total & & 296 \\
\hline
\end{tabular}




\section{DNA extraction}

The genomic DNA was extracted according to the conventional $\mathrm{NaCl}$ method described by Miller et al. (1988). DNA extraction was performed in the Physiopathology and Biochemistry of Nutrition laboratory, University of Tlemcen, Algeria, and the Molecular and Cellular Genetics laboratory (USTOMB) University of Sciences and Technology of Oran Mohamed-Boudiaf. The DNA concentration for some (Number) samples was carried out using a fluorometer device (Qubit 3 metic).

\section{PCR and fragment analysis}

This step was carried out in the Veterinary Genetic laboratory of the Hassan II Agronomic and veterinary institute, Rabat Morocco. The PCR amplification was carried out using the StockMarks kit (PE Applied Biosystems. Foster City. California. the USA) which includes 17 microsatellite markers (VHL20, HTG4, AHT4, HMS7, HTG6, AHT5, HMS6, ASB23, ASB2, HTG10, HTG7, HMS2, HMS3, ASB17, Lex3, HMS1, CA425) used routinely for the identification and parentage control of horses. The final concentration for each reagent used for PCR are stock Buffer $=1.25 \mu \mathrm{L}, \mathrm{D}$ ntp $=2 \mu \mathrm{L}$, Taq $=0.25 \mu \mathrm{L}$, $\mathrm{H} 2 \mathrm{O}=1.5 \mu \mathrm{L}$ and $1.5 \mu \mathrm{L}$ DNA, with the final Mixed PCR volume is $8.5 \mu \mathrm{L}$. The PCR was carried out in Applied Biosystems Thermal Cycler (GeneAmp PCR 2700 system).. The DNA was first denatured at $95{ }^{\circ} \mathrm{C}$ for 15 minutes before undergoing 30 amplification cycles. Each cycle was comprising a denaturation step at $95^{\circ} \mathrm{C}$ for 30 seconds, a hybridization step at $60{ }^{\circ} \mathrm{C}$ for 1 minute, and an elongation step of 46 seconds at $72^{\circ} \mathrm{C}$. After the 30 amplification cycles, A final extension lasts 60 minutes at $72{ }^{\circ} \mathrm{C}$ to optimize the action of Taq polymerase. PCR fragment was resolved on an ABI PRISM 3500 (Applied Biosystems), and data were analyzed using GENEMAPER 5 software (PE Applied Biosystems. Foster City. California, USA).

\section{Data analysis}

The number of alleles per locus $(\mathrm{Na})$, mean number of alleles (MNa), the effective number of alleles $(\mathrm{Ne})$, polymorphic information content (PIC), observed (Ho) and expected heterozygosity $(\mathrm{He})$, average heterozygosity $\left(\mathrm{H}^{\mathrm{a}}\right)$, Hardy-Weinberg equilibrium and null allele frequencies were calculated using GenAlEx 6.5 (New Brunswick, NJ) (Peakall and Smouse 2012), POPGENE Version 1.32 (Alberta, Canada) (Yeh et al. .1997), CERVUS 3.0.3 (Bozeman, MT) (Marshall et al. 2006). The genetic distance and the construction of a dendrogram (neighborjoining method) for the different Breeds studied was carried out using phylip-3.695 software (Felsenstein, 2013). The bootstrap resampling methodology (1000 replicates) was performed to test the robustness of the dendrogram topology using the same software. Wright's Fstatistics $\left(\mathrm{F}_{\mathrm{it}}, \quad \mathrm{F}_{\mathrm{is}}, \mathrm{F}_{\mathrm{st}}\right)$ (Wright 1931; Weir and Cockerham1984) were calculated using POPGENE (Yeh et al. 1997). Nei's gene diversity $\left(\mathrm{H}_{\mathrm{t}}\right)$, diversity between breeds $\left(D_{s t}\right)$, and the coefficient of gene differentiation $\left(G_{s t}\right)$ values were calculated with FSTAT 2.9.3 software (Goudet 2001). The factorial correspondence analysis (FCA) is performed to visualize the relationships between individuals from different breeds and to test possible admixtures between the populations. AFC was computed using Genetix 4.05 (Montpellier, France) (Belkhir et al. 2000). The genetic structure of the populations was investigated using STRUCTURE 2.3.4 software (Oxford, UK) (Hubisz et al. 2009). The analysis was performed with a burn of 20,000 in length, followed by 100,000 Markov chain Monte Carlo iterations for each from K (2 to 9), with 20 replicate runs for each $\mathrm{K}$, using independent allele frequencies and an admixture model. Evanno's method (Evanno et al. 2005) was used to identify the appropriate number of clusters using DK, based on the rate of change in the $\log$ probability of the data. The optimal $\mathrm{K}$ values were selected by STRUCTURE HARVESTER (Earl and von Holdt 2012).

\section{RESULTS AND DISCUSSION}

\section{Genetic diversity within markers and breeds}

Of the 296 samples of extracted DNA, only 279 could be amplified by PCR and genotyped by the automatic sequencer; this can be explained either by contamination or by bad DNA quality. A total of 170 alleles from 17 microsatellite loci were observed. The number of alleles ranged from 5 (HTG7) to 15 (ASB17), with an average number of 10 alleles, and the average number of effective alleles was 3.97. The estimated heterozygosity $(\mathrm{He})$ value varied from 0.536 (HTG7) to 0.828 (Lex3). The content of polymorphic information (PIC) was above the information threshold (PIC> 0.5) for all microsatellites, so that the highest value is the lowest were observed for (Lex3 (0.909) and CA425 (0.742) with an overall average of 0,692 for all loci. The $\mathrm{H}^{\mathrm{a}}$ value for all loci studied was 0.714 (Table 2).

The lowest and highest observed heterozygosity (Ho) values were 0.435 for the Lex 3 microsatellite and 0.831 for the HTG7 microsatellite, respectively, with an overall average of 0.672. Wright F Statistics (Fis. Fit and Fst) described the statistically expected level of heterozygosity in the population. The mean values of Fis, Fit, and Fst were $0.053,0.102$, and 0.052 , respectively. The obtained overall (Dst) value describing the diversity between breeds was 0.025 . The overall mean of the (Gst) value determining the difference in genes was 0.033. Nei gene diversity (HT) ranged between 0.574 (HTG7) to 0.872 (Lex3). All microsatellite loci deviated from the Hardy-Weinberg equilibrium. The presence of null alleles, defined as nonamplifying alleles due to mutations at the PCR priming sites, causes overestimation of both Fst and genetic distance values. The frequency of the null allele ranged from 0.0070 (HMS6) to 0.2155 (Lex3) with an overall average of 0.043 .

The results of genetic diversity by breeds are summarized in Table 3. The average number of lower and upper alleles per locus ranged from 4.941 (Saddle) to 7.882 (Arab-Barb) with an allele number ranging from 84 alleles (Saddle) to 134 (Arab-Barb) per population. The estimated value of heterozygotes by population $(\mathrm{He})$ ranged from 0.683 (Sadle) to 0.746 (Arab-Barb). The Barb and Arabian 
breeds showed (0.685) the highest observed mean heterozygotic compared to $(0.625)$ in saddle breed (lowest value). Some 21 specific alleles with a frequency higher than $5 \%$ are identified for all breeds except (Algerian saddle and saddle) and with a relatively large number of specific alleles (05) in Arabian-Barb and Trotter breed and (04) in Barb Oi. It was determined that some of the loci studied in the eight equine breeds in this study (36 loci) are not in equilibrium with Hardy-Weinberg. On the contrary, the population structure defined by the Fis values indicates a loss of heterozygosity ranging from 0.048 (Arabic) to 0.137 (saddle).

\section{Genetic diversity between breeds}

The Molecular Analysis of Variance indicates (89\%) the total variability is mainly due between individuals within populations. $8 \%$ between individuals and $3 \%$ between populations. All Fst values estimated in Table 4 show a differentiation between the pairs of breeds ranging from 0.007 (Arabian-Barb/Barb) to 0.058 (thoroughbred/saddle).

Table 4 shows the values $\left(\mathrm{N}_{\mathrm{m}}\right)$ between the pairs of breeds of the populations studied varied between 72.97 to 3.26. In general, the pairs of the breeds Arabian-Barb/Barb shows a very high number $\left(\mathrm{N}_{\mathrm{m}}=72.97\right)$ compared to other couples of the breeds studied.

The dendrogram tree was constructed using the neighbor-joining method (Figure 2), based on the minimum Reynolds genetic distances obtained from the present study. Three different groups were observed on the dendrogram. The FCA explains $70.18 \%$ of the total variation (Figure 3). The factor analysis of the FCA correspondences confirmed the distinctive genetic character of the eight-horse breeds (Figure 3). The taxa appear separated into three groups as in the dendrogram (Figure 2), group 1, which represents the indigenous populations and Saddle (the Barb, Arabian-Barb, Saddle Algerian, Saddle and Barb Oi). The foreign breeds are represented by group 2 (Arabian) and group 3 (Thoroughbred English, French trotter).

The Bayesian clustering method has proven to be powerful analytical tools for identifying genetic structure in data sets (Evanno et al. 2005). This method, based on the second-order probability of variation of $\mathrm{K}$ (DK), showed a clear peak at $\mathrm{K}=3$ (Table 5) The Arabian breed (AR), Thoroughbreds (PS) and French Trotter (TF) breeds were separated from other populations after the first calculation clusters $(K=2)$. The Arabian breed (AR) is separated from the Thoroughbreds (PS), and French Trotter (TF) breeds at $K=3$. At $K=9$, Thoroughbreds (PS) and French Trotter (TF) breeds were separated into their clusters. The Barb, the Arabian Barb, the Algerian saddle, the saddle, and the Barb Oi showed relatively the same genetic structure. . The results of the STRUCTURE analysis containing different numbers of clustering performed to determine the population structure of the studied breeds are displayed in Figure 4. The structure of genetic investigation confirms the dendrogram and FCA results.

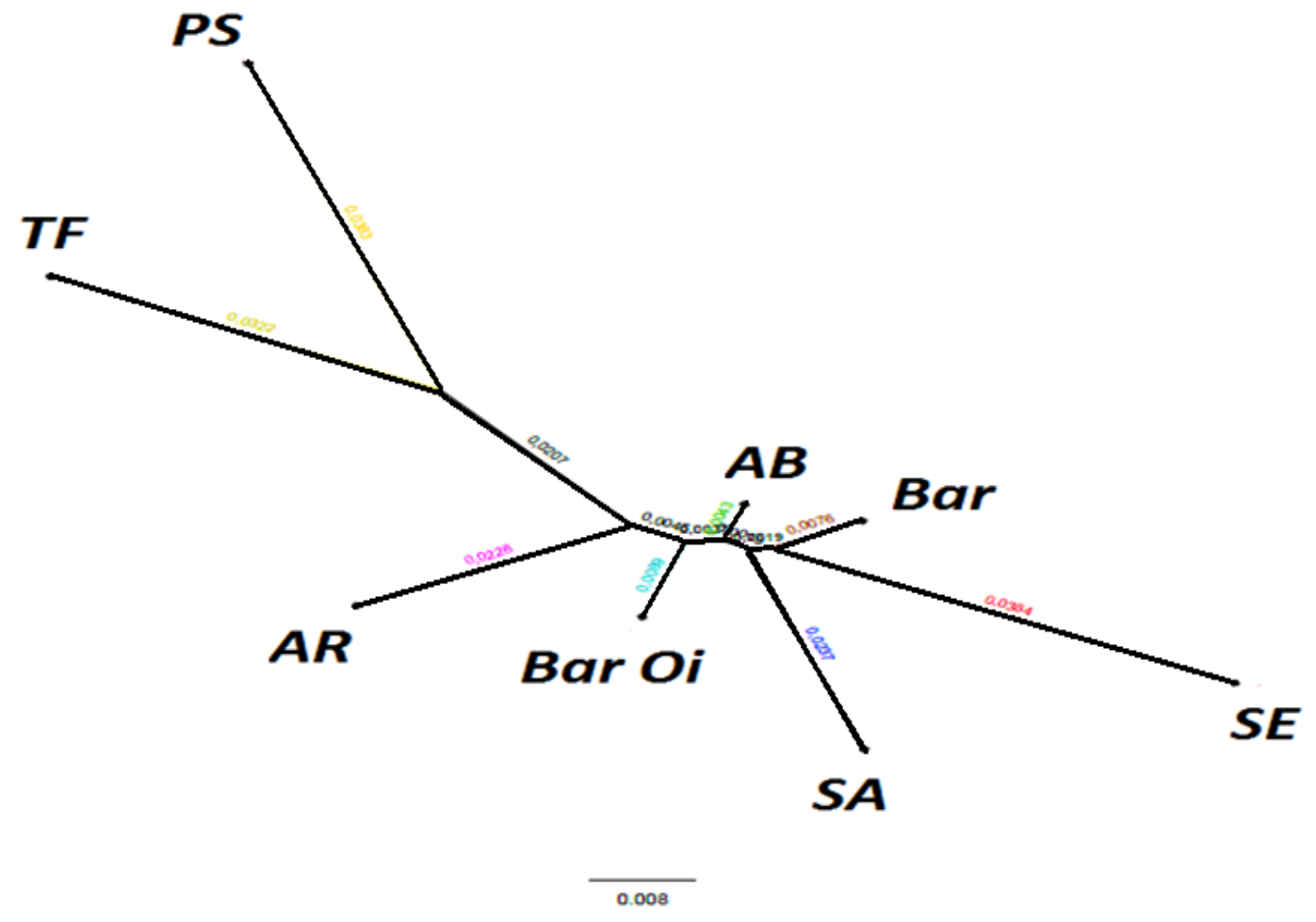

Figure 2. Dendrogram based on minimum genetic Raynolds distances between 8 breeds (Bootstrap resampling methodology (1000 replicas)). Bar. Barb, Bar Oi. Origin Barb unknown, AB. Arabian-Barb, AR. Arabian; PS. Thoroughbred (Pur sang); TF. French Trotter, SA. Algerian saddle, SE. Saddle 
Table 2. Values of the genetic parameters for each chosen locus and in all equine breeds studied

\begin{tabular}{|c|c|c|c|c|c|c|c|c|c|c|c|c|c|c|c|c|c|c|}
\hline Loci & $\mathbf{N}$ & Allelic range, bp & $\mathbf{R a}$ & $\mathbf{N a}$ & $\mathrm{Ne}$ & PIC & Ho & He & $\mathbf{H}^{\mathbf{a}}$ & Fis & Fit & Fst & Dst & Gst & Ht & $\mathrm{Nm}$ & HW & F(Null) \\
\hline VHL20 & 276 & $86-106$ & 7.103 & 11 & 5.639 & 0.893 & 0.831 & 0.815 & 0.8145 & -0.017 & 0.035 & 0.051 & 0.029 & 0.034 & 0.861 & 4.652 & $* * *$ & 0.0094 \\
\hline HTG4 & 279 & $125-137$ & 4.357 & 7 & 2.732 & 0.791 & 0.639 & 0.626 & 0.6255 & -0.017 & 0.045 & 0.061 & 0.029 & 0.043 & 0.669 & 3.879 & $* * *$ & 0.0293 \\
\hline AHT4 & 278 & $144-160$ & 5.226 & 9 & 3.954 & 0.832 & 0.755 & 0.740 & 0.7401 & -0.021 & 0.015 & 0.035 & 0.012 & 0.016 & 0.769 & 6.972 & $* * *$ & 0.0239 \\
\hline HMS7 & 276 & $169-185$ & 5.762 & 10 & 4.344 & 0.872 & 0.701 & 0.759 & 0.7589 & 0.074 & 0.129 & 0.060 & 0.033 & 0.041 & 0.811 & 3.908 & $* * *$ & 0.0403 \\
\hline HTG6 & 279 & $80-102$ & 3.807 & 9 & 2.791 & 0.792 & 0.659 & 0.624 & 0.6241 & -0.056 & 0.041 & 0.092 & 0.052 & 0.076 & 0.691 & 2.469 & $* * *$ & 0.0180 \\
\hline AHT5 & 279 & $131-145$ & 4.923 & 8 & 3.715 & 0.836 & 0.723 & 0.727 & 0.7269 & 0.001 & 0.072 & 0.071 & 0.042 & 0.053 & 0.786 & 3.279 & $* * *$ & 0.0162 \\
\hline HMS6 & 277 & $158-170$ & 4.601 & 8 & 2.929 & 0.771 & 0.728 & 0.655 & 0.6547 & -0.117 & -0.076 & 0.037 & 0.015 & 0.021 & 0.683 & 6.493 & $* * *$ & 0.0070 \\
\hline ASB23 & 277 & $183-211$ & 5.720 & 11 & 4.783 & 0.879 & 0.641 & 0.785 & 0.7846 & 0.187 & 0.218 & 0.038 & 0.013 & 0.016 & 0.82 & 6.290 & $* * *$ & 0.0835 \\
\hline ASB2 & 271 & $222-254$ & 5.940 & 12 & 4.524 & 0.878 & 0.773 & 0.757 & 0.7572 & -0.021 & 0.024 & 0.044 & 0.02 & 0.025 & 0.794 & 5.370 & $* * *$ & 0.0099 \\
\hline HTG10 & 265 & $86-106$ & 7.023 & 10 & 5.322 & 0.893 & 0.794 & 0.805 & 0.805 & 0.013 & 0.066 & 0.054 & 0.031 & 0.036 & 0.853 & 4.397 & $* * *$ & 0.0191 \\
\hline HTG7 & 279 & $119-129$ & 3.304 & 5 & 2.213 & 0.692 & 0.513 & 0.536 & 0.5363 & 0.043 & 0.103 & 0.063 & 0.026 & 0.045 & 0.574 & 3.700 & $* * *$ & 0.0304 \\
\hline HMS2 & 204 & $217-239$ & 6.219 & 11 & 4.190 & 0.855 & 0.730 & 0.731 & 0.7307 & 0.000 & 0.076 & 0.076 & 0.046 & 0.058 & 0.792 & 3.053 & $* * *$ & 0.0183 \\
\hline HMS3 & 278 & $148-172$ & 5.723 & 11 & 4.009 & 0.861 & 0.540 & 0.739 & 0.7392 & 0.270 & 0.306 & 0.049 & 0.021 & 0.027 & 0.78 & 4.848 & $* * *$ & 0.1147 \\
\hline ASB17 & 250 & $95-123$ & 7.274 & 15 & 5.336 & 0.891 & 0.826 & 0.802 & 0.802 & -0.030 & 0.020 & 0.048 & 0.026 & 0.031 & 0.844 & 4.985 & $* * *$ & 0.0124 \\
\hline Lex3 & 236 & $99-166$ & 7.288 & 14 & 5.923 & 0.909 & 0.435 & 0.828 & 0.8285 & 0.474 & 0.499 & 0.046 & 0.017 & 0.02 & 0.872 & 5.195 & * & 0.2155 \\
\hline HMS1 & 278 & $172-190$ & 3.891 & 8 & 2.642 & 0.753 & 0.587 & 0.615 & 0.6147 & 0.045 & 0.070 & 0.026 & 0.005 & 0.007 & 0.633 & 9.310 & $* * *$ & 0.0445 \\
\hline CA425 & 245 & $224-244$ & 4.928 & 11 & 2.558 & 0.742 & 0.556 & 0.595 & 0.5949 & 0.065 & 0.099 & 0.036 & 0.011 & 0.017 & 0.619 & 6.640 & $* * *$ & 0.0438 \\
\hline Mean & & & 5.476 & 10 & 3.977 & 0.832 & 0.672 & 0.714 & 0.714 & 0.053 & 0.102 & 0.052 & 0.025 & 0.033 & 0.756 & 5.026 & & 0.043 \\
\hline
\end{tabular}

Note: Na: The number of alleles, Ne: the Effective number of alleles, PIC: Content of the polymorphic information, Ho: Heterozygosity observed, He: Expected heterozygosity, Ha: Average heterozygosity, FIS, FIT, FST: Wright's F-statistics Wright 1931; Weir et Cockerham. 1984); HT: The diversity of Nei genes, DS

Table 3. Measurement of genetic diversity by breed for the 17 loci studied

\begin{tabular}{|c|c|c|c|c|c|c|c|c|c|}
\hline \multirow{2}{*}{ Breeds } & \multirow{2}{*}{ MNA } & \multirow{2}{*}{$\mathbf{R a}$} & \multirow{2}{*}{$\begin{array}{c}\text { Ho } \\
\text { Mean/SE }\end{array}$} & \multirow{2}{*}{$\begin{array}{c}\text { He } \\
\text { Mean/SE }\end{array}$} & \multirow{2}{*}{ Fis } & \multirow{2}{*}{ HWE } & \multicolumn{3}{|c|}{ NPA } \\
\hline & & & & & & & $>5 \%$ & $<5 \%$ & Total \\
\hline Bar & 7.706 & 5.256 & $0.685 \pm 0.033$ & $0.721 \pm 0.023$ & 0.059 & 2 & I & 3 & 3 \\
\hline Bar OI & 7.529 & 5.526 & $0.676 \pm 0.037$ & $0.735 \pm 0.027$ & 0.098 & 5 & & 4 & 4 \\
\hline $\mathrm{AB}$ & 7.882 & 5.783 & $0.676 \pm 0.035$ & $0.746 \pm 0.025$ & 0.102 & 8 & l & 5 & 5 \\
\hline $\mathrm{AR}$ & 6.824 & 5.034 & $0.685 \pm 0.028$ & $0.712 \pm 0.024$ & 0.048 & 4 & l & 3 & 3 \\
\hline $\mathrm{TF}$ & 6.529 & 4.951 & $0.680 \pm 0.037$ & $0.714 \pm 0.025$ & 0.067 & 6 & I & 5 & 5 \\
\hline PS & 5.529 & 4.672 & $0.672 \pm 0.034$ & $0.700 \pm 0.025$ & 0.065 & 3 & l & 1 & 1 \\
\hline SA & 6.118 & 5.068 & $0.678 \pm 0.044$ & $0.699 \pm 0.033$ & 0.061 & 2 & l & l & I \\
\hline SE & 4.941 & 4.707 & $0.625 \pm 0.063$ & $0.683 \pm 0.023$ & 0.137 & 6 & I & I & I \\
\hline
\end{tabular}

Note: MNA: mean number of alleles; FIS: within-breed heterozygote deficiency; HWE: number of loci not in the Hardy-Weinberg equilibrium (p<0.05); NPA: number of private alleles. Bar. Barb, Bar Oi. Origin Barb unknown, AB. Arabian-Barb, AR. Arabian; PS. Thoroughbred (Pur sang); TF. French Trotter, SA. Algerian saddle, SE. Saddle. 
Table 4. Fst estimated (below the diagonal) as a measure of genetic distance between horse breeds and the number of effective migrants per generation $\mathrm{N}_{\mathrm{m}}$ (above the diagonal)

\begin{tabular}{|c|c|c|c|c|c|c|c|c|}
\hline Bar & Bar OI & $\mathbf{A B}$ & $\mathbf{A R}$ & TF & PS & SA & SE & \\
\hline- & 25.50 & 72.97 & 6.06 & 4.41 & 3.38 & 19.32 & 18.18 & Bar \\
\hline 0,011 & - & 52.92 & 8.94 & 4.54 & 4.95 & 22.60 & 9.60 & Bar OI \\
\hline 0,007 & 0,008 & - & 10.65 & 4.98 & 4.17 & 25.45 & 19.71 & $\mathbf{A B}$ \\
\hline 0,025 & 0,018 & 0,016 & - & 3.39 & 3.96 & 6.14 & 7.23 & $\mathbf{A R}$ \\
\hline 0,035 & 0,035 & 0,032 & 0,043 & - & 4.90 & 3.83 & 3.70 & TF \\
\hline 0,045 & 0,035 & 0,039 & 0,040 & 0,036 & - & 3.53 & 3.26 & PS \\
\hline 0,017 & 0,017 & 0,016 & 0,029 & 0,046 & 0,049 & - & 11.80 & SA \\
\hline 0,023 & 0,031 & 0,024 & 0,034 & 0,052 & 0,058 & 0,033 & - & SE \\
\hline
\end{tabular}

Note: Bar: Barb, Bar Oi: Origin Barb unknown, AB: Arabian-Barb, AR: Arabian, PS: Thoroughbred (Pur sang); TF: French Trotter, SA: Algerian saddle, SE: Saddle.

Table 5. Show the appropriate number of clusters using DK, by STRUCTURE HARVESTER (Earl and vonHoldt 2012)

\begin{tabular}{lcccccc}
\hline K & Reps & Mean LnP(K) & Stdev LnP(K) & Ln'(K) & $\left|\operatorname{Ln}^{\prime \prime}(\mathbf{K})\right|$ & Delta K \\
\hline 2 & 20 & 15590.0900 & 1.7244 & - & - & 63.337271 \\
3 & 20 & 15299.9700 & 2.8623 & 290.120000 & 181.290000 & 10.442686 \\
4 & 20 & 15191.1400 & 3.1745 & 108.830000 & 33.150000 & 7.51080 \\
5 & 20 & 15115.4600 & 8.7241 & 75.680000 & 65.525000 & 1.400859 \\
6 & 20 & 15105.3050 & 11.1003 & 10.155000 & 15.550000 & 0.489474 \\
7 & 20 & 15110.7000 & 29.7053 & -5.395000 & 14.540000 & 0.954881 \\
8 & 20 & 15130.6350 & 90.5976 & -19.935000 & 86.510000 & - \\
9 & 20 & 15237.0800 & 221.5462 & 106.445000 & - & - \\
\hline
\end{tabular}

Note: The highlight zone is to show the suitable cluster number $(\mathrm{K})$ in structure analysis results $(\mathrm{k}=3)$

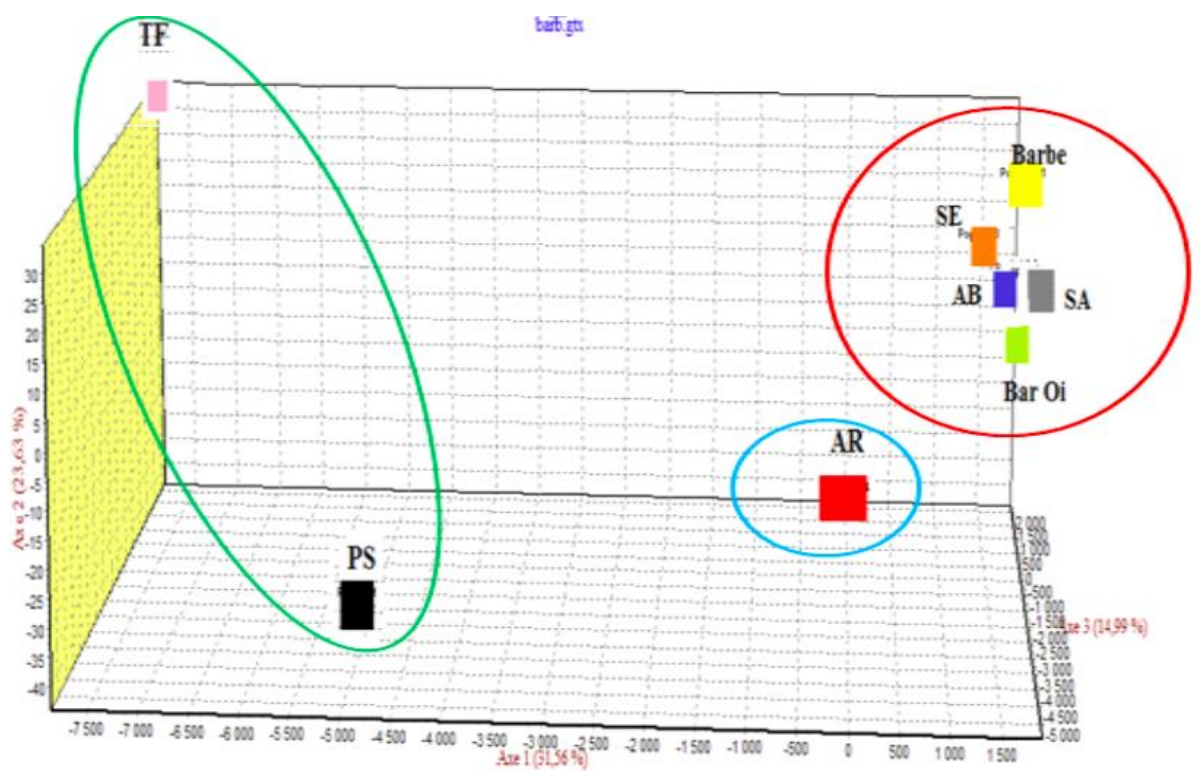

Figure 3. The factorial correspondence analysis (FCA) results showing the relationship between 8 breeds. Bar: Barb, Bar Oi: Origin Barb unknown, AB: Arabian-Barb, AR: Arabian; PS: Thoroughbred (Pur sang), TF: French Trotter, SA: Algerian saddle, SE: Saddle 


\section{Discussion}

Genetic diversity within markers and breeds

A total of 170 alleles from 17 microsatellite loci were observed for the 279 horses studied. These results were slightly similar to 177 alleles observed by a Korean study on 3880 Halla horses (Seo et al. 2016). However, it was much higher than other studies using microsatellite markers, i.e 157 alleles observed in 96 individuals with 20 polymorphic microsatellites (Chauhan et al. 2011),118 alleles detected in 1032 thoroughbreds (Mario et al. 2019), 137 alleles were detected for 200 horses (Piro et al. 2019), 130 alleles Szilvia et al. (2013) and 115 alleles were observed in the 300 horses in Tunisia (Ouled Ahmed et al. 2018) and 123 alleles obtained in the 201 horses in Algeria (Berber et al. 2016). On the other hand, it was much lower than the 330 alleles detected in the 26 native Chinese horse breeds using 27 microsatellite markers by Ling et al. (2011) and much lower than the 282 alleles identified in 74 animals for the 29 microsatellites used by Dorji et al. (2018).

The results of this study may indicate that the majority of markers are very informative, and all the markers showed a significant deviation from the Hardy-Weinberg equilibrium. According to Botstein et al. (1980), if the values (Pic and Ho) obtained exceed 0.6 and 0.5 , respectively, the microsatellite markers are considered as very informative. In this study, all markers have a PIC mean greater than 0.5 . On the other hand, five markers (Lex3, HMS3, HTG7, HMS1, and CA425) did not reach the 0.6 of heterozygote observed. The overall frequency of null alleles represented in our study with a lower average of 0.2 (Nullf threshold <0.2) indicating that the genotyping has a very low error rate (Dakin and Avise 2004). The mean value of our genotypes $(\mathrm{Dst}=2.5 \%)$ was lower than (Dst=7.6\%) observed in Ouled Ahmed et al. 2018 for the same microsatellite markers. These results showed a low genetic diversity between the equine populations studied. Indeed, the obtained Gst mean value (3.3\%) in our study is higher than that observed (1.2\%) by Piro et al. (2019). Moreover, much lower than that observed in Tunisian equine breeds (8.8\%) (Ouled Ahmed et al. 2018). In fact, the average value of the Gst stressed that $3.3 \%$ of the total genetic variation results from differences between populations. In all other respects, it can be said that $96.7 \%$ of genetic variation is caused by the difference between individuals.

Molecular genetic identification was an important factor as well as performance recordings and morphological evaluations for equine breeding. The present study was conducted to detect the genetic variability and the structure of the equine population through microsatellite markers on eight equine breeds bred in Algeria. Twenty-one private alleles are represented with frequencies below 5\% in all breeds, except the Algerian Saddle and Saddle breed, where no private allele was detected (Table 3 ). These results are superior to the 20 and 12 private alleles identified by Putnová et al. 2019, in Czech horses and Berber et al.2014, in Algerian breeds, respectively.

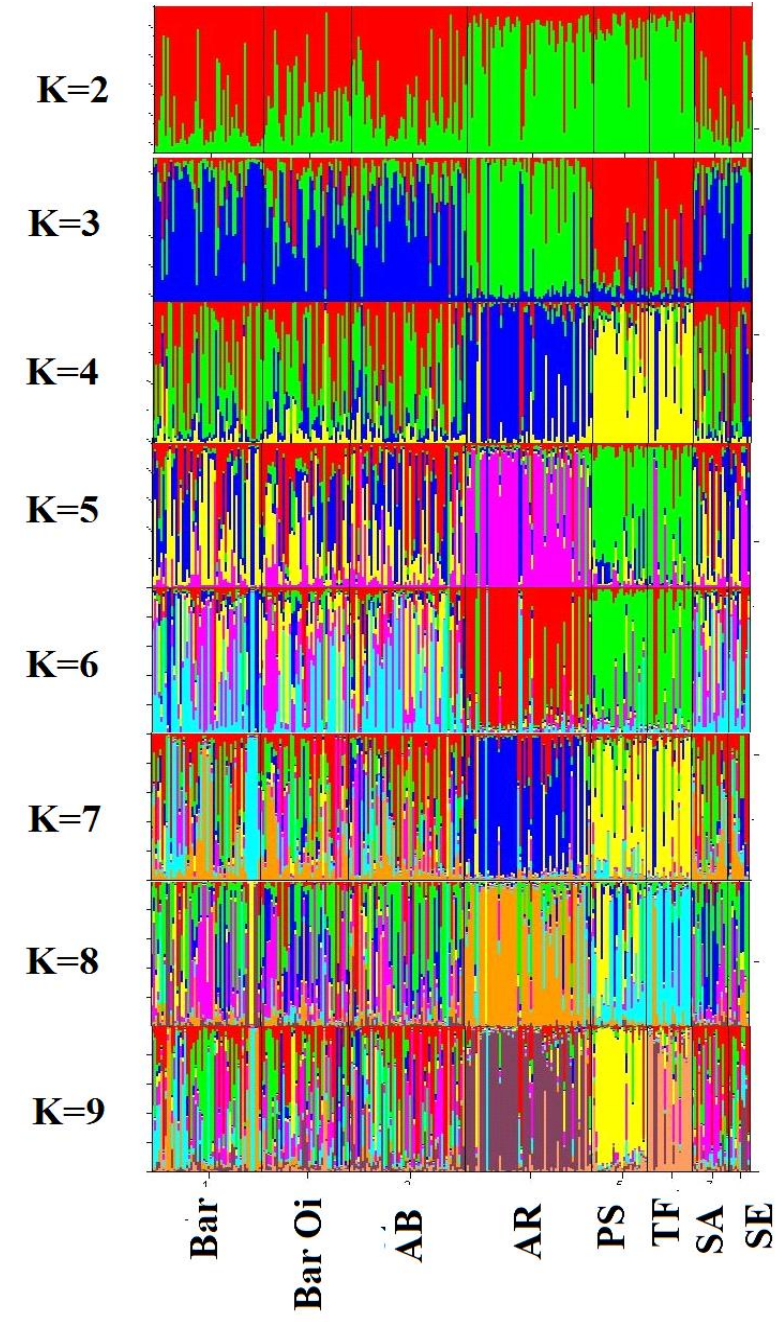

Figure 4. Estimation of the population structure with different $\mathrm{K}$ values (supposing $K=2$ to 9). Bar: Barb, Bar Oi: Origin Barb unknown, AB: Arabian-Barb, AR: Arabian; PS: Thoroughbred (Pur sang); TF: French Trotter, SA: Algerian saddle, SE: Saddle

We have also observed a relatively large number of specific alleles in the Arabian-Barb, Trotter, and Barb Oi Breeds, which is in favor of their differentiation with the other populations. It was also observed that in the Barb, the saddle, the Arabian-Barb, and the Barb Oi breeds, the Fis value was significantly positive. In Algeria, most of the same stallions are used for the Barb and the Arabian-Barb breed mating and are reared in the same national stud. On the other hand, the Saddle and Barb Oi breed mating is managed independently by breeders throughout the country but always using a very small quantity of bloodstock, which can explain the low level of heterozygosity (Benhamadi et al. 2017, 2019).

The eight populations studied have a lower value of observed heterozygosity than that of expected heterozygote $(\mathrm{Ho}=0.672$ and $\mathrm{He}=0.714)$. This probably due to the type of livestock management (Jemmali et al. 2015), the same report was obtained by Piro et al. 2019 and Ouled Ahmed et al. 2018. Indeed, the expected mean heterozygous for the eight breeds studied is among the highest and most 
heterozygous reported for other equine populations studied by (Piro et al. 2019, Senju et al. 2016 and Khanshour et al. 2019, 2013) But similar to the study conducted by( Berber et al. 2014 and Bigi et al. 2012 ), and lower than that obtained by (Ouled Ahmed et al. .2018, Seyedabadi et al. 2017 and Cortés et al. 2017).

\section{Genetic diversity between breeds}

Our results showed genetic differentiation for all the populations studied, but the group of Barb/Arabian-Barb and Barb Oi breeds demonstrated a very close genetic structure. The level of differences is explained by $5.2 \%$ of the total genetic variation, and all the loci contribute to this differentiation. Concerning Fst, the values being moderately low and similar for all systems studied, but very significant $(\mathrm{p}<0.001)$. The overall value of the Fst was much higher than the $0.3 \%$ and $0.6 \%$ obtained by Jemmali et al. 2015 and Dorji et al. 2018, respectively, and slightly similar to the $5 \%$ reported by the study of Berber et al. 2014. However, it was smaller $10 \%$ than reported by (Petersen et al. 2013). The high value of Fst in these studies is probably related to the fact that these works have studied breeds without genetic flew between them (Breeds horse/riding, heavy horses, ponies). In contrast, in our study, all the breeds analyzed are not isolated, and in general, the breeders practice an anarchic reproduction between them explaining the lower Fst value.

The divergence between the horse breeds studied was assessed using different approaches (Genetic distances, factorial analysis of FCA, and Clustering method). These three methods, based on genetic relationships, gave approximately similar results. Globally there is genetic differentiation between native Algerian horses and other breeds, and the same results are reported by Berber et al. 2014. The neighbor-joining tree (DR) showed a clear subdivision of the breeds, and the Arabian-Barb horse was closer to the Barb horses, Barb Oi horse, Algerian saddle horses, and saddle breeds. The thoroughbred and French trotting breeds are separated from the native breeds, and the Arabian horses have taken an intermediate position (Figure 3).

This result can be explained by a certain influence of the Arabian breed in the formation of a breed of origin in more recent years. The genetic proximity of the four indigenous breeds Barb, Barb Oi, Arabian-Barb, and saddle Algerian have also been demonstrated using the FCA and the Bayesian grouping. This approach gives more precise information on the relationships between the breeds. However, our estimates of the native breeds (Barb and Arabian-Barb) are similar to those reported by (Berber et al. 2014).

In conclusion, the results from this study are the first to recount the genetic diversity and constitution of equine breeds from Algeria. Overall, these breeds had high levels of significant genetic variability as per different genetic diversity parameters applied in this study such as a relatively large number of alleles specific. Therefore, data on genetic diversity estimated by assimilating within and between breed variances may inform preservation strategies and the better establishment of priorities. The mismanagement of the breeding of some of these breeds like the Barb, Saddle, Arabian-Barb, and Barb Oi breeds also can be explained by the values of Fis, which are positive. In addition, this study found that equine breeds in Algeria belong to three major groups that could be preserved independently to uphold their genetic diversity. Generally, these findings provide the fundamental step in the direction of judicious decision-making before the development of genetic enhancement and preservation programs without interfering with the uniqueness of equine breeds in Algeria.

\section{ACKNOWLEDGEMENTS}

We would like to thank the partners who provided samples: the Haras National CHAOUCHAOUA of Tiaret and the National Office for the Development of Equine and Camel Breeding (ONDEEC). We would like to thank the team of the Veterinary Genetics Laboratory of the Hassan II Agronomic and Veterinary Institute, Rabat Morocco, were the molecular analysis was performed. We also thank Amar Khaled Belalia, Prof Aumassip Kadri G., and the association Adjr. Big thanks for Tabet Aoul Mohammed, Tabet Aoul Hichem and the association Nadi Forsen Tlemcen, A special thanks to Ms. Imane Meghelli, Dr. Djahdou Ahmed, Dr. Tifiel Hakim, Dr. Brahimi Youcef, Jamil Abed El Mojib, Bouandasse Amer, Madani Labbaci, and all genetics team of the University of Tlemcen, Algeria for their kind collaboration.

\section{REFERENCES}

Ahmed Rayane. 2015. Parution du livre de Ahmed Rayane: "Le Barbe dans sa première greteur". Publié le 7 Septembre 2015 par LAGHOUATI.ISBN978-9947-0-4308-0.

Belkhir K, Borsa P, Goudet J, Chikhi L, Bonhomme F. 2001. Genetix: Logiciel sous WindowsTM pour la genetique des populations. Laboratoire Genome et Populations, CNRS UPR 9060, Université Montpellier II, France.

Benhamadi MA, Kamel M, Gaouar SBS. 2016. Mémoire master. Caractérisation morphométrique de la race équine Barbe dans le Nord-Ouest de l'Algérie. tlemcen.dz/snvstu/opac_css/doc_num.php?explnum_id=1861.

Benhamadi MA, Mezouar K, Benyarou M, Bouendasse A, Gaouar SBS. 2017. Morphometric characterization of the equine barb breeds in northwest of Algeria. Genet Biodiv J 1 (2): 48-65.

Benhamadi MA, Kamel M, Gaouar SBS. 2019. Livre intitulé "Caractérisation morphomètrique de la Breed équine Barb dans l'Algérie".

Berber N, Gaouar S, Leroy G, Kdidi S, Tabet Aouel N, Mehtar NS. 2014 Molecular characterization and differentiation of five horse breeds raised in Algeria using polymorphic microsatellite markers. J Anim Breed Genet 131 (5): 387-394. DOI: 10.1111/jbg.12092

Berber N. 2016. [Thèses Doctorat]. Constitution d'une biothéque d'ADN équin. Caractérisation génétique des Breeds équines en Algérie par l'étude des microsatellites.

Bigi D, Perrotta G. 2012. Structure génétique et différenciation du cheval italien Catria. J Heredity 103 (1): 134-139. DOI: 10.1093/jhered/esr121

Botstein D, White RL, Skolnick M, Davis RW. 1980. Construction of a genetic linkage map in man using restriction fragment length polymorphisms. Am J Hum Genet 32 (3): 314-331.

Chauhan M, Gupta AK, Dhillon S. 2011. Diversité génétique et structure des populations de trois races de chevaux indiennes. Mol Biol Rep 38: 3505-3511. DOI: $10.1007 / \mathrm{s} 11033-010-0461-\mathrm{z}$ 
Cortés O, Dunner S, Gama LT, Martınez AM, Delgado JV, Ginja C, Jimenez LM, Jordana J, Luis C, Oom MM, Sponenberg DP, Zaragoza P, Biohorse Consortium, Vega-Pla JL. 2017. The legacy of Columbus in American horse populations assessed by microsatellite markers. J Anim Breed Genet 134 (4): 340-350. DOI: 10.1111/jbg.12255

DAD-IS. 2018. Browse by species and country: Algeria, Horse. Accessed in October 2018.

Dakin EE, Avise JC. 2004. Microsatellite null alleles in parentage analysis. Heredity 93: 504-509.

Dorji J, Tamang S, Tshewang T, Dorji T, Dorji TY. 2018. Genetic diversity and population structure of three traditional horse breeds of Bhutan based on 29 DNA microsatellite markers. PLoS ONE 13 (6): e0199376. DOI: 10.1371/journal.pone.0199376

Élise Rousseau. 2014. Tous les chevaux du monde, Delachaux and Niestlé, Septembre 2014.

Felsenstein J. 2013. PHYLIP (Phylogeny Inference Package) version 3.695. Department of Genome Sciences, University of Washington, Seattle.

Goudet J. 2001. FSTAT, A Program to Estimate and Test Gene Diversities and Fixation Indices (Version 2.9.3). Universite de Lausanne, Lausanne, Suisse (available at http://www2.unil.ch/popgen/softwares/fstat.htm last accessed 1 October 2011)

Hubisz MJ, Falush D, Stephens M, Pritchard JK. 2009. Inferring weak population structure with the assistance of sample group information. Mol Ecol Resour 9 (5): 1322-1332. DOI: 10.1111/j.17550998.2009.02591.x

Jemmali B, Haddad Mm, Ouled Ahmed H, Lasfer F, Ben Aoun B, Ezzar S, Kribi S, Gtari S, Ezzaouia Mh, Rekik B. 2015. Investigation de la diversité génétique des races Barbe et Arabe Barbe en Tunisie. J New Sci Agric Biotechnol21 (1): 948-956.

Khanshour A, Conant E, Juras R, Cothran EG. 2013. Microsatellite analysis of genetic diversity and population structure of Arabian horse populations. J Hered 104 (3): 386-398. DOI: 10.1093/jhered/est003

Khanshour AM, Hempsey EK, Juras R, Cothran EG. 2019. Genetic characterization of Cleveland bay horse breed. Diversity 11 (10): 174 DOI: $10.3390 / \mathrm{d} 11100174$.

Ling YH, Ma YH, Guan WJ, Cheng YJ, Wang YP, Han JL, Mang L, Zhao QJ, He XH, Pu YB, Fu BL. 2011. Evaluation of the genetic diversity and population structure of Chinese indigenous horse breeds using 27 microsatellite markers. Anim Genet 42 (1): 56-65. DOI 10.1111/j.1365-2052.2010.02067.x

Mario C, Valentina R, Raffaella R, Vincenzo C. 2019. Genetic diversity of the Italian thoroughbred horse population. Italian J Anim Sci 18 (1): 538-545. DOI: 10.1080/1828051X.2018.1547128
Marshall TC. 2006. CERVUS, 3,0, Cervus is a computer program for assignment of parents to their offspring using genetic markers, Cervus, a Windows package for parentage analysis using likelihood approach, CERVUS was written by Tristan Marshall (1998/2006) http://www, fieldgenetics, com.

Miller SA, Dykes DD, Polesky HF. 1988. A simple salting out procedure for extracting DNA from human nucleated cells. Nucleic Acids Res 16 (3): 1215 . DOI: $10.1093 /$ nar/16.3.1215

Ouled Ahmed H, Fatnassi M, Ferchichi H, Baccouche R, Lasfar F, Zaouia M, Ben Younes A, Haddad M, Trimeche A .2018. Analyse génétique et relations phylogénétiques du cheval Barbe par l'utilisation des microsatellites. Revue Méd Vét 169 (4-6): 103-109.

Peakall R, Smouse PE. 2012. GenAlEx 6,5: Genetic analysis in Excel, population genetic software for teaching and research - an update. $\begin{array}{llll}\text { Bioinformatics } & 28 & (19): & 2537-2539 .\end{array}$ 10.1093/bioinformatics/bts460

Petersen JL, Mickelson JR, Cothran EG, Andersson LS, Axelsson J, Bailey E, et al. 2013. Genetic diversity in the modern horse illustrated from genome-wide SNP data. PLoS ONE 8 (1): e54997. DOI: 10.1371/journal.pone.0054997

Piro M, Alyakine H, Ezzaouia M, Lasfar F, Ouled Ahmed H, Ouragh L. 2019. Analyse génétique and relations phylogénétiques du cheval Barbe par l'utilisation des microsatellites. Rev Mar Sci Agron Vét 7 (1): 149-157.

Putnová L, Štohl R, Vrtková I. 2019. Using nuclear microsatellite data to trace the gene flow and population structure in Czech horses. Czech $\mathrm{J}$ Anim Sci 64: 67-77

Senju N, Tozaki T, Kakoi H, Shinjo A, Matsuyama R, Almunia J, Takasu M. 2016. Genetic diversity of the Yonaguni horse based on polymorphisms in microsatellites and mitochondrial DNA. J Vet Med Sci 79 (2): 425-431. DOI: 10.1292/jvms.16-0040

Seo JH, Park KD, Lee HK, Kong HS. 2016. Genetic diversity of Halla horses using microsatellite markers. J Anim Sci Technol 58 (1): 40. DOI: 10.1186/s40781-016-0120-6.

Seyedabadi HR, Savar Sofla S. 2017. Microsatellite analysis for parentage verification and genetic characterization of the Turkmen horse population. Kafkas Univ Vet Fak Derg 23 (3): 467-471. DOI: $10.9775 / \mathrm{kvfd} .2016 .17096$

Szilvia K, Katalin P, Ante I, Bogumila J, Tomasz P, András J, Sándor M. 2013. Genetic characterization and population bottleneck in the Hucul horse based on microsatellite and mitochondrial data. Biol J Linnean Soc 109 (1): 54-65. DOI: 10.1111/bij.12023.

Yeh FC, Yang RC, Boyle TBJ, at al. 1997. Popgene: The user-friendly shareware for population genetic analysis. Edmonton, University of Alberta, Canada. 